\title{
Monitoring arthropods in a tropical landscape: relative effects of sampling methods and habitat types on trap catches
}

\author{
Olivier Missa ${ }^{1}$, Yves Basset $^{2}{ }^{\square}$, Alfonso Alonso ${ }^{3}$, Scott E. Miller $^{4}$, \\ Gianfranco Curletti ${ }^{5}$, Marc De Meyer ${ }^{6}$, Connal Eardley ${ }^{7}$, Mervyn W. Mansell ${ }^{8}$ and \\ Thomas Wagner'
}

(1) Department of Biology, University of York, PO Box 373, York, YO10 5YW, UK

(2) Smithsonian Tropical Research Institute, Apartado 0843-03092, Balboa, Ancon, Panama City, Republic of Panama

(3) Smithsonian Institution/Monitoring and Assessment of Biodiversity Program, 1100 Jefferson Drive, S.W. Suite 3123, Washington, DC 20560-0705, USA

(4) Smithsonian Institution, Washington, DC 20013-7012, USA

(5) Museo Civico di Storia Naturale, Cas. Post. 89, 10022 Carmagnola (TO), Italy

(6) Royal Museum for Central Africa, Leuvensesteenweg 13, 3080 Tervuren, Belgium

(7) Plant Protection Research Institute, Private Bag X134, Queenswood, Pretoria, 0121, South Africa

(8) Department of Zoology and Entomology, University of Pretoria, Pretoria, 0002, South Africa

(9) Institut für Integrierte Naturwissenschaften-Biologie, Universität Koblenz-Landau, Universitätsstr. 1, 56070 Koblenz, Germany

$\checkmark$ Yves Basset

Email: bassety@si.edu

\begin{abstract}
To discuss the challenge of monitoring multi-species responses of tropical arthropods to disturbance, we considered a large dataset $\left(4 \times 10^{5}\right.$ individuals; 1,682 morphospecies representing 22 focal taxa) based on the work of parataxonomists to examine the effects of anthropogenic disturbance on arthropods at Gamba, Gabon. Replication included three sites in each of four different stages of forest succession and land use after logging, surveyed during a whole year with four sampling methods: pitfall, Malaise, flight-interception and yellow pan traps. We compared the suitability of each sampling method for biological monitoring and evaluated statistically their reliability for 118 arthropod families. Our results suggest that a range of sampling methods yields more diverse material than any single method operated with high replication. Multivariate analyses indicated that morphospecies composition in trap catches was more strongly influenced by habitat type than by sampling methods. This implies that for multi-species monitoring, differences in trap efficiency between habitats may be neglected, as far as habitat types remain well contrasted. We conclude that for the purpose of monitoring large arthropod assemblages in the long-term, a protocol based on operating a set of different and non-disruptive traps appears superior in design than summing a series of taxa-specific protocols.
\end{abstract}

\section{Introduction}


The Millennium Ecosystem Assessment (2005) report makes clear that: (1) loss in biodiversity due to human activities has been more rapid in the past 50 years than at any time in human history; (2) the most important drivers of biodiversity loss are habitat change (including loss and fragmentation of forests) and climate change; (3) in the tropics, habitat change contributes much more to biodiversity loss than climate change and this situation will continue for a significant period (Sala et al. 2000); and (4) rates of biodiversity loss are projected to accelerate. In particular, tropical forests are likely to turn into extinction hotspots (May et al. 1995) and these extinctions will primarily involve arthropods (Dunn 2005).

Because of their short generation time, invertebrates respond quickly to modifications of their environment (Kremen et al. 1993; Basset et al. 2001) and may be more discriminating in this regard than vertebrates (Moritz et al. 2001). Arthropod populations are thought to be sensitive to short-term impacts of land management, as well as to longer-term general ecosystem changes (Kremen et al. 1993; Underwood and Fisher 2006). Relatively high number of arthropods can be easily collected with a variety of techniques without harming their populations. For these various reasons, they represent choice organisms for biological monitoring (Kremen et al. 1993).

The usual goal of a species inventory is to document as completely as possible the taxonomy and ecology of taxa within a certain area (see Longino and Colwell 1997 for a good example related to ants). In contrast, biological monitoring seeks to repeat sampling over time to identify population patterns (Stork et al. 1995; Niemelä 2000; Yoccoz et al. 2001; Underwood and Fisher 2006; Conrad et al. 2007). Monitoring goals may include detecting the presence of invasive species; detecting population trends of threatened, endangered or keystone species; evaluating land management decisions; or assessing ecosystem change (Underwood and Fisher 2006). Our research framework relates to the latter and seeks to assess the effects of anthropogenic disturbance, such as land conversion and clearance, on tropical arthropods. This subject is not well understood and warrants further investigations since perhaps $80-90 \%$ of tropical taxa have never been the focus of tropical conservation studies (review in Lewis and Basset 2007).

It is increasingly clear that a multi-species approach, including functional guilds, appears to be better than using indicator species to monitor the responses of tropical invertebrates to disturbance (Kremen et al. 1994; Didham et al. 1996; Lawton et al. 1998; Kotze and Samways 1999; Basset et al. 2001). The task of monitoring a sufficient number of taxa at various locations with adequate time may appear daunting. In practice, working with parataxonomists (i.e., local assistants trained by professional biologists) with adequate taxonomic feedback can help to alleviate these problems and ensure that statistical replicates are representative of the system studied (Basset et al. 2004b).

Entomologists have devised quantitative protocols to survey or monitor specific taxa in the tropics, such as for example ants (Longino and Colwell 1997; Agosti et al. 2000; Underwood and Fisher 2006), termites (Jones and Eggelton 2000), or butterflies (Sparrow et al. 1994; DeVries and Walla 2001). While some recommendations are available to survey whole arthropod assemblages in the tropics (e.g., Noyes 1989; 
Gadagkar et al. 1990; Stork and Brendell 1993; Basset et al. 1997; Adis et al. 1998; Kitching et al.2001), few guidelines exist for designing monitoring protocols targeting multi-assemblages in the tropics (Finnamore 1997; see Rohr et al. 2007 for one temperate example). There are multiple reasons for this, owing notably to complex issues of sampling methodology, spatio-temporal replication to characterize well assemblages and taxonomic impediment (Niemelä 2000; Rohr et al. 2007). This contribution focuses on sampling methodology and emphasizes the three following questions: (a) which trap/method may be suitable for monitoring? (b) Which higher taxa are best collected by particular trapping method, when several trapping methods are used? (c) Does trap efficiency vary between different habitat types?

With regard to the first question, entomologists have devised an impressive range of techniques and traps (e.g., Southwood and Henderson 2000). The challenge is less about collecting insects, but rather how to use available methods with maximum efficiency, and how best to interpret the resulting data. Sampling methods can be broadly classified in three categories. The first category allows estimating population density by surveying a defined area/volume of habitat (e.g., visual counts, soil coring). The second category includes traps that passively collect arthropods as they move in the habitat (e.g., pitfall, Malaise and flight interception traps). In this case, differing levels of activity among species complicate the interpretation of these trap catches. However, large numbers of individuals can often be collected with relatively little effort. The last category uses the attraction of arthropods for a particular scent, food or visual cue to lure and trap them (e.g., light, pheromone and colored pan traps). These techniques can be very effective for focal taxa but their results are the most difficult to interpret as catches are affected by population density, individual activity and stimulus attraction, all three of which tend to differ among species (Southwood and Henderson 2000).

When the emphasis is on comparing species densities, sampling methods belonging to the first category are often the best choice. However, since they are often destructive and labor intensive, they may be unsuitable for biological monitoring. For baseline surveys and biological monitoring, trapping techniques may be preferable, especially when comparing different habitats or the same habitat over time. Trapping methods used in biological monitoring must fulfill several criteria. Ideally, they should: be simple, inexpensive, non-destructive and non-disturbing to the study system; have a negligible impact on arthropod populations; be easy to deploy, service and maintain in the field; behave more or less consistently across sites (including both control and impact sites) with respect to the profile of arthropods collected; be relatively insensitive to abiotic factors (or the potential effects of abiotic factors on trap catches should be measurable); quickly provide representative baseline data and repeatable results with low stochastic variance; produce seasonal and annual replicates of the same sampling units; provide a variety of material and/or be efficient for specific focal taxa; provide quality material and taxonomically tractable taxa; and avoid redundancy of information (Kitching et al. 2001). These quantitative criteria preclude using specific but mainly qualitative protocols developed by taxonomists for their favorite taxa. 
While many papers consider the relative merits of modifying a particular sampling method, relatively few compared meaningfully different methods of sampling terrestrial arthropods for biological monitoring (reviews in Muirhead-Thomson 1991; Basset et al. 1997; Southwood and Henderson 2000; Kitching et al. 2001). Comparisons have often been impeded by low spatial and taxonomic replication. Choice of methods relied more on scientific traditions than on rigorous statistic analyses. Nevertheless, four of the most used sampling methods for arthropods are furthermore recommended for biological monitoring: pitfall, Malaise, flight-interception and yellow pan traps (Finnamore 1997; Niemelä 2000; Southwood and Henderson 2000; Kitching et al. 2001; Rohr et al. 2007). The first three are passive traps whereas yellow pan traps collect arthropods that are attracted to a small area of water in a yellow container. In this contribution, we consider these four methods, which may be complemented by automatic light traps, if one is more concerned about nocturnal insects (Wolda et al. 1998; Kitching et al. 2001).

Several authors have emphasized the value of using a range of sampling methods for inventorying tropical arthropods (Noyes 1989; Gadagkar et al. 1990; Stork 1994; Basset et al. 1997; Longino and Colwell 1997; Kitching et al. 2001). If one of the goals of biological monitoring is assessing the long-term effects of ecosystem changes on multiple arthropod assemblages with a range of sampling methods, then the relative affinities of particular taxa for particular methods need to be quantified for a sound interpretation of monitoring data. As for question (b), above, the entomological literature is surprisingly scarce on applying rigorous statistics to estimating arthropod affinity for particular trapping methods. A major exception is Kitching et al. (2001), who identified subset of both trapping methods and target taxa across a latitudinal transect spanning from Australia to Borneo. However, these authors discussed mainly biodiversity inventorying and detailed information only at the ordinal level. An optimal design for a monitoring programme would require some information on the relative affinity of taxa for particular trapping method at least at the familial level (see Rohr et al. 2007 for a temperate example).

With regard to question (c) above, a dissimilar trap efficiency in different habitats may result from the effect of habitat structure on the trappability of different taxa (Melbourne 1999), from faunistic differences between habitats, or from both factors. This issue has rarely been well quantified (see discussions for pitfall, Malaise and light traps in Bowden 1982; Longino and Colwell 1997; Melbourne 1999; King and Porter 2005) and deserves particular attention when designing a monitoring programme assessing long-term ecosystem changes, for example.

Here we consider a study based on the work of trained parataxonomists in Gabon, which examines the effects of a wide anthropogenic gradient of disturbance on a range of focal arthropod taxa that represent diverse taxonomic and functional guilds. Replication included three sites in each of four different stages of forest succession and land use after logging, surveyed during a whole year with four sampling methods recommended for biological monitoring (pitfall, Malaise, flight-interception and yellow pan traps). The major results of this study are reported elsewhere (Basset et al. 2004a, 2008). Although this specific study was not designed as a monitoring exercise, we believe that its scope in 
terms of diversity of habitats surveyed, sampling methods used, sample size, replication, and taxonomic coverage allow us to discuss some issues which may be important for designing monitoring programmes assessing the effects of ecosystem changes on multiple assemblages of arthropods in the tropics. In this context, our key questions are:

- Do the four sampling methods used in this study appear suitable for biological monitoring? Additionally, what are their relative efficiency (in terms of abundance and species richness) and complementarity to collect rapidly baseline information?

- Which taxa are most likely to be collected in a baseline study using these four sampling methods?

- What are the relative effects of sampling methods per se and habitat types on the composition of trap catches?

\section{Methods \\ Study area and sites}

The study area was in the Shell Gabon oil concession of Gamba, within the Gamba Complex of Protected Areas in south-east Gabon (see Alonso et al. 2006 for background and botanical information). The Gamba oil field includes a mosaic of old growth secondary rainforests, younger secondary rainforests and savanna areas, resulting mainly from anthropogenic action. Primary rainforests are absent from the Gamba oil field, following the selective logging of Okoumé (Aucoumea klaineana Pierre). The mean annual temperature in the area is $26^{\circ} \mathrm{C}$ and annual rainfall amounts to $2,093 \mathrm{~mm}$ per year, with the major dry season from June to August (Alonso et al. 2006). The earliest cultivated crop gardens of notable size were established near the town as recently as 1998.

We considered four distinct habitats of increasing anthropogenic disturbance (i.e., increasing forest clearing and introduction of exotic vegetation) and selected three sites (replicates) within each habitat. The four habitat types were: (a) the understorey of the interior of old secondary rainforests, 'old forests'; (b) the understorey of the edge of young secondary rainforests, 'young forests'; (c) an area of rainforest cleared to install oil rigs and subsequently invaded by savanna, 'savanna'; and (d) cultivated crop gardens, 'gardens'. At the time of the study, there were no substantial plantations in the area and these four habitat types were predominant in the Gamba oil field. Salient characteristics of the study sites (coded A-L) are indicated in Table 1 (see also Basset et al. 2004a). Table 1 Main characteristics of study sites within the Shell-Gabon Gamba oil field

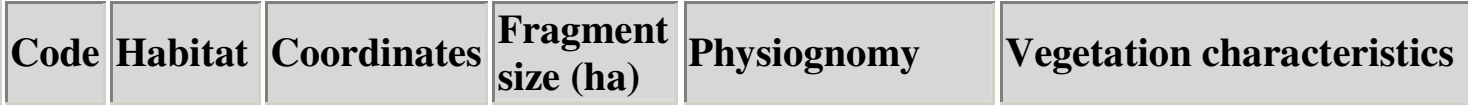




\begin{tabular}{|c|c|c|c|c|c|}
\hline Code & Habitat & Coordinates & $\begin{array}{l}\text { Fragment } \\
\text { size (ha) }\end{array}$ & Physiognomy & Vegetation characteristics \\
\hline \multirow[b]{2}{*}{$A^{a}$} & \multirow[b]{2}{*}{$\begin{array}{l}\text { Old } \\
\text { forest }\end{array}$} & $02^{\circ} 42^{\prime} 20^{\prime \prime} \mathrm{S}$ & \multirow[b]{2}{*}{700} & \multirow[b]{2}{*}{$\begin{array}{l}\text { Secondary forest, } \\
\text { tallest } \\
\text { trees }=45 \mathrm{~m}, \\
\text { sandy soil }\end{array}$} & \multirow{2}{*}{$\begin{array}{l}\text { Neochevalierodendron } \\
\text { stephanii (A. Chevalier) } \\
\text { Léonard dominant, } \\
\text { Diospyros zenkeri (Gurke) } \\
\text { F. White and D. vermoesent } \\
\text { De Wild common }\end{array}$} \\
\hline & & $09^{\circ} 59^{\prime} 49^{\prime \prime} \mathrm{E}$ & & & \\
\hline \multirow[b]{2}{*}{ B } & \multirow[b]{2}{*}{$\begin{array}{l}\text { Old } \\
\text { forest }\end{array}$} & $02^{\circ} 42^{\prime} 54^{\prime \prime} \mathrm{S}$ & \multirow[b]{2}{*}{84} & \multirow[b]{2}{*}{$\begin{array}{l}\text { Secondary forest, } \\
\text { tallest } \\
\text { trees }=45 \mathrm{~m}, \\
\text { sandy soil }\end{array}$} & \multirow{2}{*}{$\begin{array}{l}\text { Neochevalierodendron } \\
\text { stephanii dominant, } \\
\text { Diospyros zenkeri, D. } \\
\text { vermoeseni and Palisota } \\
\text { ambigua CB. Clarke } \\
\text { common }\end{array}$} \\
\hline & & $10^{\circ} 00^{\prime} 00^{\prime \prime} \mathrm{E}$ & & & \\
\hline \multirow[b]{2}{*}{$C^{\mathrm{a}}$} & \multirow[b]{2}{*}{$\begin{array}{l}\text { Old } \\
\text { forest }\end{array}$} & $02^{\circ} 44^{\prime} 27^{\prime \prime} \mathrm{S}$ & \multirow[b]{2}{*}{28} & \multirow[b]{2}{*}{$\begin{array}{l}\text { Secondary forest, } \\
\text { tallest } \\
\text { trees }=40 \mathrm{~m}, \text { but } \\
\text { many small trees } \\
10-20 \text { m tall, } \\
\text { sandy soil }\end{array}$} & \multirow{2}{*}{$\begin{array}{l}\text { Diospyros vermoeseni and } \\
\text { D. conocarpa Gurke ex K. } \\
\text { Schum common, } P \text {. } \\
\text { ambigua and Trichoscypha } \\
\text { acuminata Engler less } \\
\text { common }\end{array}$} \\
\hline & & $10^{\circ} 00^{\prime} 11^{\prime \prime} \mathrm{E}$ & & & \\
\hline \multirow[b]{2}{*}{$D^{a}$} & \multirow[b]{2}{*}{$\begin{array}{l}\text { Young } \\
\text { forest }\end{array}$} & $02^{\circ} 45^{\prime} 38^{\prime \prime} \mathrm{S}$ & \multirow[b]{2}{*}{12} & \multirow{2}{*}{$\begin{array}{l}\text { Secondary forest, } \\
\text { tallest } \\
\text { trees }=20 \mathrm{~m}, \\
\text { many small trees } \\
\text { and bushes, sandy } \\
\text { soil }\end{array}$} & \multirow{2}{*}{$\begin{array}{l}\text { Palisota ambigua, } \\
\text { Aframomum } \mathrm{sp} \text {. and } \\
\text { Rauvolfia } \text { sp. common; one } \\
\text { pioneer Musanga } \\
\text { cecropioides } \mathrm{R} \text {. Br. ex } \\
\text { Tedlie present }\end{array}$} \\
\hline & & $10^{\circ} 01^{\prime} 37^{\prime \prime} \mathrm{E}$ & & & \\
\hline \multirow[b]{2}{*}{$\mathrm{E}$} & \multirow[b]{2}{*}{$\begin{array}{l}\text { Young } \\
\text { forest }\end{array}$} & $02^{\circ} 46^{\prime} 08^{\prime \prime} \mathrm{S}$ & \multirow[b]{2}{*}{19} & \multirow{2}{*}{$\begin{array}{l}\text { Secondary forest, } \\
\text { very open canopy, } \\
\text { tallest } \\
\text { trees }=30 \mathrm{~m}, \\
\text { swampy soil }\end{array}$} & \multirow[b]{2}{*}{$\begin{array}{l}\text { Xylopia hypolampra Mildb. } \\
\text { and Xylopia spp. dominant }\end{array}$} \\
\hline & & $10^{\circ} 02^{\prime} 25^{\prime \prime} \mathrm{E}$ & & & \\
\hline \multirow[b]{2}{*}{$F^{\mathrm{a}}$} & \multirow[b]{2}{*}{$\begin{array}{l}\text { Young } \\
\text { forest }\end{array}$} & $02^{\circ} 47^{\prime} 32^{\prime \prime} \mathrm{S}$ & \multirow[b]{2}{*}{166} & \multirow[b]{2}{*}{$\begin{array}{l}\text { Secondary forest, } \\
\text { plot at the edge of } \\
\text { a thin tongue of } \\
\text { forest connected } \\
\text { to a large forested } \\
\text { area; tallest } \\
\text { trees = } 30 \mathrm{~m} \text {, } \\
\text { important re- } \\
\text { growth in the } \\
\text { understorey, } \\
\text { sandy soil }\end{array}$} & \multirow[b]{2}{*}{$\begin{array}{l}\text { Pachypodanthium staudtii } \\
\text { Engl. and Diels, Diospyros } \\
\text { vermoeseni, Palisota } \\
\text { ambigua, Leptactina mannii } \\
\text { Hook.f., Ouratea sulcata } \\
\text { (Van Tiegh.) Keay, } \\
\text { Sacoglottis gabonensis } \\
\text { (Baillon)Urb. and Bertiera } \\
\text { subsessilis Hiern present }\end{array}$} \\
\hline & & $10^{\circ} 03^{\prime} 45^{\prime \prime} \mathrm{E}$ & & & \\
\hline$G$ & Savanna & $02^{\circ} 42^{\prime} 51^{\prime \prime} \mathrm{S}$ & 2.7 & Surrounded by & Borreria verticillata $(\mathrm{L})$. \\
\hline
\end{tabular}




\begin{tabular}{|c|c|c|c|c|c|}
\hline \multirow[t]{2}{*}{ Code } & \multirow[t]{2}{*}{ Habitat } & Coordinates & \multirow{2}{*}{$\begin{array}{l}\text { Fragment } \\
\text { size (ha) }\end{array}$} & \multirow{2}{*}{$\begin{array}{l}\text { Physiognomy } \\
\text { forest; isolated } \\
\text { bushes and trees, } \\
\text { sandy soil, bare } \\
\text { soil = 50\% }\end{array}$} & \multirow{2}{*}{$\begin{array}{l}\text { Vegetation characteristics } \\
\text { GFW Mey and two } \\
\text { unidentified Poaceae } \\
\text { dominant, Cyperus tenax } \\
\text { Boeck and Dracaena sp. } \\
\text { present }\end{array}$} \\
\hline & & $09^{\circ} 59^{\prime} 55^{\prime \prime} \mathrm{E}$ & & & \\
\hline \multirow[b]{2}{*}{$\mathrm{H}$} & \multirow[b]{2}{*}{ Savanna } & $02^{\circ} 44^{\prime} 11^{\prime \prime} \mathrm{S}$ & \multirow[b]{2}{*}{3.0} & \multirow[b]{2}{*}{$\begin{array}{l}\text { Surrounded by } \\
\text { forest, sandy soil, } \\
\text { bare soil = } 25 \%\end{array}$} & \multirow{2}{*}{$\begin{array}{l}\text { Borreria verticillata, } \\
\text { Dracaena sp. and one } \\
\text { unidentified Poaceae } \\
\text { dominant, Cyperus halpan } \\
\text { J. Kern and Heterotis } \\
\text { decumbens (Pal.Beauv.) H. } \\
\text { Jacques-Félix present }\end{array}$} \\
\hline & & $10^{\circ} 00^{\prime} 22^{\prime \prime} \mathrm{E}$ & & & \\
\hline \multirow[b]{2}{*}{ I } & \multirow[b]{2}{*}{ Savanna } & $02^{\circ} 48^{\prime} 23^{\prime \prime} \mathrm{S}$ & \multirow[b]{2}{*}{2.5} & \multirow{2}{*}{$\begin{array}{l}\text { Surrounded by } \\
\text { forest, sandy soil, } \\
\text { bare soil = } 25 \%\end{array}$} & \multirow{2}{*}{$\begin{array}{l}\text { Merremia tridentata Hallier } \\
\text { f., Cyperus tenax and one } \\
\text { unidentified Poaceae } \\
\text { dominant }\end{array}$} \\
\hline & & $10^{\circ} 03^{\prime} 21^{\prime \prime} \mathrm{E}$ & & & \\
\hline \multirow[b]{2}{*}{$\mathrm{J}$} & \multirow[b]{2}{*}{ Garden } & $02^{\circ} 44^{\prime} 47^{\prime \prime} \mathrm{S}$ & \multirow[b]{2}{*}{2} & \multirow[b]{2}{*}{$\begin{array}{l}\text { Sandy soil } \\
\text { fertilized with } \\
\text { compost }\end{array}$} & \multirow{2}{*}{$\begin{array}{l}\text { Amaranth, aubergine, } \\
\text { cabbage, carrot, lettuce, } \\
\text { pepper, spinach, sweet } \\
\text { pepper, tomato and water } \\
\text { melon }\end{array}$} \\
\hline & & $10^{\circ} 01^{\prime} 10^{\prime \prime} \mathrm{E}$ & & & \\
\hline \multirow{2}{*}{$\mathrm{K}$} & \multirow{2}{*}{ Garden } & $02^{\circ} 43^{\prime} 36^{\prime \prime} \mathrm{S}$ & \multirow{2}{*}{0.5} & \multirow{2}{*}{$\begin{array}{l}\text { Clayish sand } \\
\text { fertilized with } \\
\text { compost }\end{array}$} & \multirow{2}{*}{$\begin{array}{l}\text { Aubergine, banana, maize, } \\
\text { manioc, pepper, pineapple, } \\
\text { spinach, sugar cane and tarc }\end{array}$} \\
\hline & & $10^{\circ} 02^{\prime} 06^{\prime \prime} \mathrm{E}$ & & & \\
\hline \multirow[b]{2}{*}{ L } & \multirow[b]{2}{*}{ Garden } & $02^{\circ} 44^{\prime} 09^{\prime \prime} \mathrm{S}$ & \multirow[b]{2}{*}{0.8} & \multirow{2}{*}{$\begin{array}{l}\text { Sandy soil } \\
\text { fertilized with } \\
\text { compost }\end{array}$} & \multirow{2}{*}{$\begin{array}{l}\text { Amaranth, aubergine, } \\
\text { cabbage, cucumber, gombo, } \\
\text { pepper, sorrel, spinach and } \\
\text { tomato }\end{array}$} \\
\hline & & $10^{\circ} 01^{\prime} 06^{\prime \prime} \mathrm{E}$ & & & \\
\hline
\end{tabular}

For gardens, the main crops cultivated during the study period are listed

${ }^{\mathrm{a}}$ Sites equipped with a flight-interception trap

\section{Arthropod collecting and processing}

Each site was equipped with an identical set of traps recommended for the biological monitoring of the flying and epigaeic arthropods of the understorey and litter (Finnamore 1997; Niemelä 2000; Southwood and Henderson 2000; Kitching et al. 2001; Rohr et al. 2007). At each site, one ground Malaise trap (hereafter MT), four ground yellow pan traps (YPT) and five pitfall traps buried in the ground (PT) were used. In addition, four flight-intercept traps were also set up at forest sites (FIT; Table 1 ).

The collecting surface of one MT was $2.7 \mathrm{~m}^{2}$ (model similar to Townes 1972 ; Santé Traps, 739 Cooper Drive, Lexington, Kentucky, USA 40502). Collecting fluid was $70 \%$ ethanol. YPT were $27 \mathrm{~cm}$ in diameter by $8 \mathrm{~cm}$ deep and filled with a mixture of water 
(ca. 80\%), $70 \%$ ethanol (ca. 20\%) and a few drops of liquid detergent to break the surface tension of the water. They were placed in the soil so that the rim was level with ground surface, thus also intercepting crawling arthropods (Finnamore 1997). PTs were small 0.5-1 plastic cups ( $6 \mathrm{~cm}$ in diameter) filled with the same water, ethanol and detergent mixture. At each site, a MT occupied the center of the set of traps, with four PTs established to the north, south, east and west, $10 \mathrm{~m}$ distant from the MT. Four YPTs were set up at equal distances between the PT, again $10 \mathrm{~m}$ distant from the MT. The fifth PT was placed $30 \mathrm{~m}$ north of the MT. In addition, 4 FITs were hung $3 \mathrm{~m}$ off the ground above the fifth PT, in four of the six forest sites. The collecting surface of one FIT was about $4 \mathrm{~m}^{2}$ (Santé Traps; model similar to Springate and Basset 1996). All of these traps have specific advantages and limitations, as discussed for example in Adis (1979) and Basset et al. (1997).

The 120 traps operated for 3 days each week and were intended to be surveyed weekly (=one survey) from July 2001 to July 2002. However, the amount of material collected required us to spread surveys and eventually only 38 surveys were obtained during the above period (12 in the dry season and 26 in the wet season). The longest gap between two surveys was one month (December 2001). A team of eight parataxonomists was trained and supervised by a professional entomologist throughout the project (see Basset et al. $2004 \mathrm{~b}$ for a detailed discussion of this strategy). The material collected was first sorted into families or higher taxa by the parataxonomists (see exceptions below). The material belonging to 22 focal taxa (Table 2) was isolated and pinned, and each individual was identified by a unique specimen number. The focal taxa were sorted to morphospecies (i.e., unnamed species diagnosed using standard taxonomic techniques) by the parataxonomists. Formal taxonomic study of this material is ongoing but subsamples of the material belonging to seven taxa have been examined by taxonomists (Table 2). The rationale for selecting the 22 focal taxa were (a) being well represented in the samples (so that much information was retained); (b) being workable taxonomically; (c) taxonomists having expressed interests in working on the material; and (d) representation of a variety of functional guilds and orders (Table 2 ).

Table 2 Focal taxa sorted by parataxonomists

\begin{tabular}{|l|l|l|l|l|l|l|l|l||}
\hline Focal taxa & Order $^{\mathbf{a}}$ & Guild $^{\mathbf{b}}$ & Ind & Indm $^{\mathbf{c}}$ & \multicolumn{2}{|l|}{ Mor } & Spp. & Authority \\
\hline Mantodea & Ma & Pr & 98 & 56 & 22 & - & - \\
\hline Acrididoidea $^{\mathrm{d}}$ & Or & Lc & 1,129 & 360 & 40 & - & - \\
\hline Fulgoroidea & e & He & Ss & 4,022 & 2,842 & 242 & - & - \\
\hline Membracidae & He & Ss & 37 & 36 & 15 & - & - \\
\hline Buprestidae & Co & Wo & 115 & 95 & 16 & 16 & GC \\
\hline Scarabaeidae & Co & Lc, Sc & 2,240 & 2,031 & 88 & - & - \\
\hline Coccinellidae & Co & Pr & 1,409 & 1,203 & 34 & - & - \\
\hline Histeridae & Co & Pr & 682 & 624 & 25 & - & - \\
\hline Cleridae & Co & Pr & 45 & 38 & 19 & - & - \\
\hline Tenebrionidae & Co & Sc & 839 & 644 & 60 & - & - \\
\hline Cerambycidae & Co & Wo & 278 & 149 & 53 & 51 & S. Lingafelter \\
\hline
\end{tabular}




\begin{tabular}{|c|c|c|c|c|c|c|c|}
\hline Focal taxa & Order $^{\mathrm{a}}$ & Guild $^{\mathbf{b}}$ & Ind & $\operatorname{Indm}^{\mathrm{c}}$ & Mor & Spp. & Authority \\
\hline Chrysomelidae & $\mathrm{Co}$ & $\mathrm{Lc}$ & 2,285 & 1,961 & 169 & 157 & TW \\
\hline Neuroptera $^{\mathrm{f}}$ & $\mathrm{Ne}$ & $\operatorname{Pr}$ & 235 & 152 & 25 & 25 & MWM \\
\hline Asilidae & Di & $\operatorname{Pr}$ & 409 & 351 & 50 & - & - \\
\hline Dolichopodidae $^{\mathrm{g}}$ & Di & $\operatorname{Pr}$ & 7,339 & 2,121 & 38 & - & - \\
\hline Tephritidae & Di & $\mathrm{Lc}^{\mathrm{h}}$ & 535 & 429 & 35 & - & - \\
\hline Syrphidae & Di & $\operatorname{Pr}, \mathrm{Sc}$ & 459 & 375 & 34 & 25 & C. Thompson \\
\hline Pipunculidae & Di & $\mathrm{Pa}$ & 123 & 97 & 16 & 22 & MDM; M. Foldvari \\
\hline Ichneumonidae & Hy & $\mathrm{Pa}$ & 2,302 & 1,916 & 429 & - & - \\
\hline Chalcidoidea $^{\mathrm{i}}$ & Hy & $\mathrm{Pa}$ & 4,577 & 1,315 & 179 & - & - \\
\hline Formicidae & $\mathrm{Hy}$ & An & 134,912 & na & na & - & - \\
\hline Apoidea $^{j}$ & Hy & $\mathrm{Lc}^{\mathrm{k}}$ & 1,239 & 1,060 & 93 & 51 & $\mathrm{CE}$ \\
\hline
\end{tabular}

Ind $=$ no. individuals collected; $\mathrm{Indm}=$ no. individuals morphotyped by parataxonomists; Mor $=$ total no. of morphospecies sorted by parataxonomists from Indm. Spp. = no. of species sorted by taxonomists from a sub-sample of Indm (full data presented and discussed elsewhere); Authority = taxonomist in charge of the material, abbreviated for co-authors of this article aOrders: $\mathrm{Co}=$ Coleoptera, $\mathrm{Di}=$ Diptera, $\mathrm{He}=$ Hemiptera, $\mathrm{Hy}=$ Hymenoptera, $\mathrm{Ma}=$ Mantodea, $\mathrm{Ne}=$ Neuroptera, $\mathrm{Or}=$ Orthoptera

${ }^{\mathrm{b}}$ Guilds: $\mathrm{An}=$ ants, $\mathrm{Lc}=$ leaf-chewers, $\mathrm{Pa}=$ parasitoids, $\mathrm{Pr}=$ predators, $\mathrm{Sc}=$ Scavengers , Ss $=$ sap-suckers, Wo $=$ wood-eaters (system of Moran and Southwood 1982)

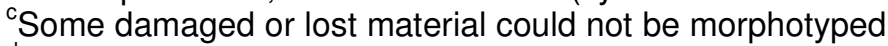

${ }^{\mathrm{I}}$ Including Acrididae, Pyrgomorphidae and many juveniles, not morphotyped

êncluding 14 families

IIncluding eight families

${ }^{9}$ Only morphotyped from July to December 2001, then kept unassigned in alcohol

hSubguild: fruit-feeders

'Only $>2 \mathrm{~mm}$ and including 13 families

'Including Apidae, Halictidae and Megachilidae

kSubguild: pollinators

There were a few exceptions to the sorting and mounting pattern. Non-insect material was mostly sorted to order. Lepidoptera were not sorted to families, since being wet material they were useless. In the Diptera, the Nematocera, Brachycera and Aschiza were treated at the family level; numerous Schizophora were often identified as Calyptera or Acalyptera because of taxonomic difficulties. A number of other taxa were identified to superfamily level for the same reasons: Coccoidea, Aphidoidea, some Cucujoidea, Chalcidoidea, Cynipoidea and Proctotrupoidea. Chalcidoidea smaller than $2 \mathrm{~mm}$ were counted, but not morphotyped. Two focal taxa that were very abundant in samples, Dolichopodidae and Formicidae, were partly processed and morphotyped. Specimens are stored at the Smithsonian Biodiversity Conservation Center in Gamba, and vouchers have been deposited at the National Museum of Natural History (Washington D.C.) and with taxonomists who helped with species identification.

\section{Statistical methods}


Our analyses often considered three datasets of increasing taxonomic resolution and accuracy: (a) higher taxa (mostly families); (b) morphospecies sorted by parataxonomists from focal taxa; and (c) species sorted by taxonomists from focal taxa. Datasets at the ordinal resolution lack discriminating power, as indicated by earlier analyses of part of the material collected (Basset et al. 2004a). We also often contrasted data related to forest vs. non-forest habitats. For most analyses, we pooled the data of a particular sampling method for a survey and considered this to be a sample $(n=38)$. One needs to recall that a sample is equivalent to three days of collecting of 60 PTs, 48 PYTs, 4 FITs and 12 MTs.

First, we compared the abundance and diversity of the material collected by the four sampling methods with a series of standard statistics and curves routinely used in ecology (Magurran 1988; Colwell 2005): Kruskal-Wallis tests, coefficient of variation, Coleman rarefaction, non-parametric Chaol estimate of species richness, evenness (=Shannon diversity index/ln[no. morphospecies/species observed]) of species rank abundance curves, and randomized species accumulation curves. We also compared the three main sampling methods (PT, YPT and MT) with regard to the shared number of morphospecies/species between methods and computed two relevant statistics: MorisitaHorn index of faunal similarity and complementarity. The Morisita-Horn index is a special case of the NESS index where sample size parameter is set to 1 and is most sensitive to common species (Grassle and Smith 1976). Complementarity between methods was estimated with the Marczewski-Steinhaus distance (proportion of all species collected by two methods that were captured by only one method; varies from 0 , when both methods share all species, to 1 , when methods have no species in common; Colwell and Coddington 1994). Most of these statistics were calculated with EstimateS version 7.5, with 50 randomizations whenever applicable (Colwell 2005).

Second, to evaluate which higher taxa were best collected by each sampling method, we used the indicator value index, which ranges from 0 (no indication) to 100 (perfect indication; Dufrêne and Legendre 1997). Perfect indication means that presence of a taxon points to a particular sampling method without error, at least with the dataset in hand. For this analysis, we considered the sum of individuals collected within higher taxa for a particular combination of site and sampling method $(12 \times 3+4=40$ samples $)$. We restricted the dataset to the most abundant higher taxa ( $\geq 40$ individuals; i.e., at least on average one individual collected in each sample; 151 higher taxa were considered). The significance of the maximum indicator value was tested for each taxon by a randomization procedure implemented in PC-ORD (Monte Carlo permutation tests; 1,000 permutations; McCune and Medford 1999).

Last, we performed multivariate analyses to estimate the relative contribution of sampling methods, habitat type and seasonality on the composition of arthropod catches, for the higher taxa, morphospecies and species datasets. For each dataset, we pooled data from a combination of sites, sampling methods and seasons $(12 \times 3 \times 2+4 \times 2=80$ samples $)$. Seasons were defined as being 'dry' (June-August) or 'wet' (other sampling months). We restricted datasets to the most abundant higher taxa ( $\geq 40$ individuals, $n=151,80$ samples), morphospecies ( $\geq 40$ individuals, $n=86,80$ samples) and species $(\geq 20$ 
individuals, $n=43$, 67 samples). First, we performed unconstrained ordinations (detrended correspondence analysis, DCA, ter Braak and Smilauer 1998) for each dataset to examine the grouping of samples with regard to sampling methods and habitat types, especially forest vs. non-forest habitats. Second, we performed constrained ordinations (canonical correspondence analysis, CCA, ter Braak and Smilauer 1998) for each dataset to evaluate the effects of independent (factor) variables. These included sampling methods (four dummy variables re-coded as advised in Leps and Smilauer 2003), habitats (four dummy variables) and seasons (two dummy variables). Partitioning of variance followed Borcard et al. (1992).

\section{Results}

Overall, 430,448 arthropods were collected during the 38 sampling events (4,712 samples), representing 31 orders and at least 218 families. The 22 focal taxa represented 17,822 individuals and 1,682 morphospecies (Table 2). Further, 347 species were sorted from the seven focal taxa which to date have been examined by taxonomists. Most individuals were collected by PTs and MTs (Table $\underline{3}$ ). Catch rates expressed per trap-day were significantly different among methods (Kruskal-Wallis test, $W=1390.9$, $P<0.001)$. MTs provided the highest catch rate, but when considering catch rates per unit surface area, PTs were most efficient, with the notable high efficiency of YPTs. Catches with YPTs also had the lowest coefficient of variation (Table 3 ). Distribution of arthropod abundance in the four habitat types was broadly similar for each of the four sampling methods, being usually high and similar at forest sites, lowest in the savanna, and intermediate to high in gardens (Table $\underline{3}$ ).

Table 3 Statistics related to the abundance and diversity of arthropod material collected by each sampling method

\begin{tabular}{|l|l|l|l|l||}
\hline Variable & PT & YPT & FIT & MT \\
\hline No. ind. collected & 148,591 & 106,963 & 30,044 & 144,850 \\
\hline $\begin{array}{l}\text { Mean } \pm \text { SE ind. collected per } \\
\text { survey }\end{array}$ & $3,910 \pm 434$ & $2,814 \pm 219$ & $791 \pm 96$ & $3,812 \pm 306$ \\
\hline CV for survey samples (\%) & 68.4 & 47.9 & 75.0 & 49.4 \\
\hline $\begin{array}{l}\text { Catch rate (mean } \pm \text { SE ind. } \\
\text { collected per trap-day) }\end{array}$ & $21.7 \pm 1.8$ & $19.5 \pm 0.9$ & $65.9 \pm 5.6$ & $105.9 \pm 6.2$ \\
\hline $\begin{array}{l}\text { Catch rate (mean } \\
\text { ind. } \times \text { day } \times \text { m }^{-2} \text { ) }\end{array}$ & 7676.3 & 341.4 & 16.5 & 39.2 \\
\hline $\begin{array}{l}\text { Mean } \pm \text { SE ind. collected per } \\
\text { survey in old forests }\end{array}$ & $1,359 \pm 253.4$ & $656.4 \pm 106.6$ & $427.6 \pm 64.0$ & $1202.8 \pm 175.9$ \\
\hline $\begin{array}{l}\text { Mean } \pm \text { SE ind. collected per } \\
\text { survey in young forests }\end{array}$ & $1326.7 \pm 249.2$ & $830.9 \pm 103.4$ & $363.1 \pm 38.8$ & $807.9 \pm 103.4$ \\
\hline $\begin{array}{l}\text { Mean } \pm \text { SE ind. collected per } \\
\text { survey in savanna }\end{array}$ & $370.3 \pm 44.5$ & $461.8 \pm 30.7$ & - & $562.7 \pm 59.5$ \\
\hline $\begin{array}{l}\text { Mean } \pm \text { SE ind. collected per } \\
\text { survey in gardens }\end{array}$ & $854.2 \pm 132.8$ & $865.8 \pm 60.0$ & - & $1238.4 \pm 121.3$ \\
\hline \hline
\end{tabular}




\begin{tabular}{|l|l|l|l|l||}
\hline Variable & PT & YPT & FIT & MT \\
\hline No. morphospecies collected & 274 & 767 & 272 & 1,108 \\
\hline No. spp. collected ${ }^{\mathrm{a}}$ & 46 & 159 & 100 & 254 \\
\hline $\begin{array}{l}\text { No. of singletons collected } \\
\text { (\% of total) }\end{array}$ & $139(50.7)$ & $379(49.4)$ & $169(62.1)$ & $504(45.5)$ \\
\hline $\begin{array}{l}\text { No. of singletons collected } \\
\text { (\% of total) in forests }\end{array}$ & $81(58.3)$ & $244(55.1$ & $169(62.1)$ & $306(57.6)$ \\
\hline $\begin{array}{l}\text { No. of singletons collected } \\
\text { (\% of total) in non-forests }\end{array}$ & $76(48.7)$ & $196(48.5)$ & - & $296(42.2)$ \\
\hline $\begin{array}{l}\text { Evenness of morphospecies } \\
\text { rank abundance curve }\end{array}$ & 0.72 & 0.75 & 0.80 & 0.81 \\
\hline $\begin{array}{l}\text { Evenness of spp. rank } \\
\text { abundance curve }\end{array}$ & 0.74 & 0.77 & 0.87 & 0.80 \\
\hline $\begin{array}{l}\text { Coleman morphospecies; } \\
\text { sample size }=1,700 \text { ind. }\end{array}$ & $265.5 \pm 0.4$ & $375.1 \pm 1.6$ & $277.5 \pm 0.3$ & $508.2 \pm 1.9$ \\
\hline $\begin{array}{l}\text { Coleman spp.: sample } \\
\text { size }=150 \text { ind. }\end{array}$ & $45.5 \pm 0.2$ & $56.7 \pm 0.7$ & $69.2 \pm 0.6$ & $68.4 \pm 0.8$ \\
\hline Chao1 \pm SE: morphospecies & $504.2 \pm 7.8$ & $1447.9 \pm 13.8$ & $677.1 \pm 12.9$ & $1842.9 \pm 12.8$ \\
\hline Chao1 \pm SE: spp. ${ }^{\text {a }}$ & $103.0 \pm 4.4$ & $299.2 \pm 6.0$ & $288.4 \pm 10.2$ & $409.9 \pm 6.2$ \\
\hline
\end{tabular}

$\mathrm{CV}=$ coefficient of variation; ind. = individuals; spp. = species

a Seven focal taxa: Table 2

Most morphospecies and species were collected by MTs and YPTs. Rarefaction indicated that this pattern remained true for morphospecies, but many species were also collected by FITs. Patterns were also broadly similar for morphospecies and species when estimating the total number of taxa present in the area or considering the evenness in rank abundance plots among sampling methods. The number of singletons collected by MTs and YPTs was appreciable. The PTs tended to have their collections dominated by a few morphospecies (Scarabaeidae and Histeridae; evenness of rank abundance plots, Table $\underline{3}$ ). PTs, YPTs and MTs collected higher proportion of singletons in forest than in non-forest habitats (Table $\underline{3}$ ). With larger sampling effort, MTs and YPTs may have collected many more species in the study area (Chao1, Table 3 ). Evenness was highest for FIT catches and lowest for PT catches (Table $\underline{3}$; morphospecies/species rank abundance plots not presented here). With the present protocol, one MT collected as many arthropods as four YPTs or five PTs; the catches of four YPTs and five PTs were 26 and $48 \%$ less diverse than one MT, respectively (Coleman rarefaction on morphospecies, Table $\underline{3}$ ).

Our sampling methods only collected a fraction of the local arthropod fauna, as suggested by morphospecies accumulation curves (Fig. 1 a; patterns were broadly similar for species and are not presented here). Also, as indicated by the rarefaction, accumulation of morphospecies was steeper for MTs than for PTs, suggesting that PTs may have sampled a higher proportion of the epigaeic fauna when compared to the proportion of flying fauna sampled by MTs. For PTs, YPTs and MTs, morphospecies accumulation curves 
were steeper in forest than in non-forest habitats, suggesting that a lower fraction of the fauna was sampled in the former than in the latter (Fig. 1b).
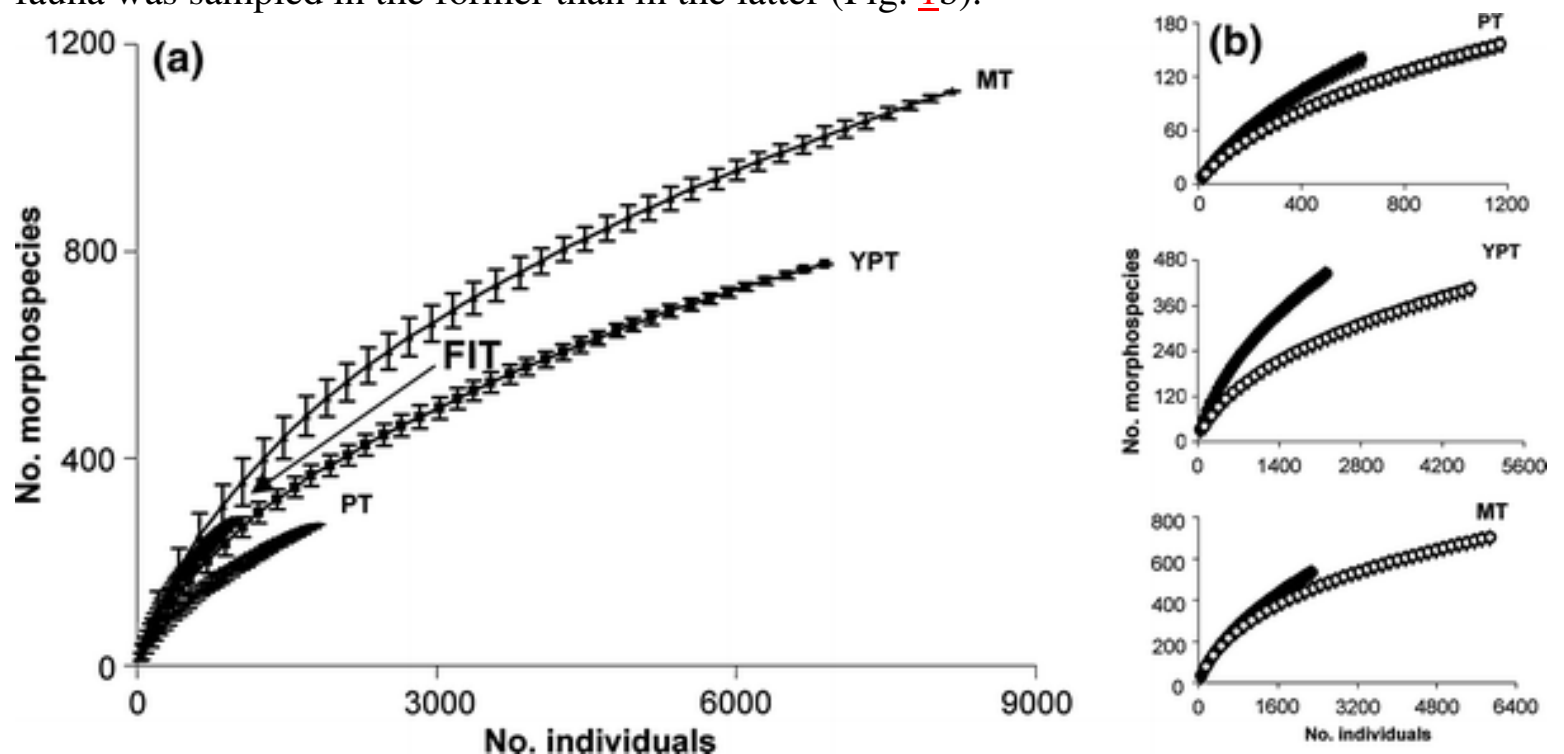

Fig. 1 Morphospecies accumulation curves (mean of 50 randomizations \pm SD) during 38 arthropod surveys, for (a) different sampling methods, all habitats being pooled; and (b) particular sampling methods operating either in forest (closed circles) or non-forest habitats (open circles)

The distribution of unique and shared taxa was broadly similar for morphospecies and species. Both for morphospecies and species, MTs produced a high proportion of unique species (55-60\%), whereas this was lower for PTs (19-26\%; Fig. 2). Only 35 morphospecies (2.1\% of total sorted) were collected by the four sampling methods. Faunal similarity was closest between the catches in MTs and FITs (Morisita-Horn indices of 0.40 for morphospecies) and furthest between the catches in MTs and PTs (Fig. 2). For both morphospecies and species, complementarity was highest between PTs and MTs (Fig. 2). 

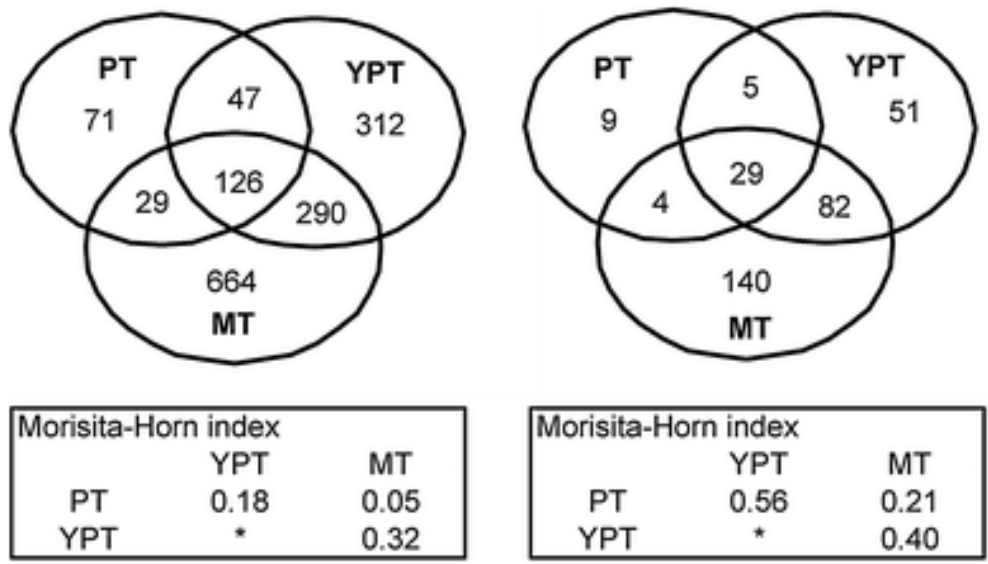

\begin{tabular}{|ccc|}
\hline \multicolumn{2}{|c|}{ Complementarity } & \\
& YPT & MT \\
PT & 0.80 & 0.87 \\
YPT & $*$ & 0.72 \\
\hline
\end{tabular}

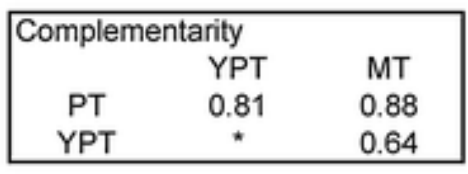

(a) Morphospecies:

22 target taxa

(b) Species:

7 target taxa

Fig. 2 Shared species statistics between the three main sampling methods (PT, YPT and MT), for (a) morphospecies and (b) species. Circles, above: no. of morphospecies/species uniques and shared between the three methods. Boxes, below: upper matrix of similarity (Morisita-Horn index) and complementarity between sampling methods

Sampling methods each collected a different spectrum of fauna and often substantial variation in trap catches existed among habitat types (Fig. 3). Furthermore, the distribution of a few abundant taxa equally well collected by the three main sampling methods was not uniform across habitats (PT, YPT and MT; Formicidae, Collembola, Phoridae, Acalyptera, Calyptera, Cicadellidae and Scelionidae; $G$-tests on $3 \times 4$ matrices, all with $P<0.001$ ), suggesting that different sampling methods collect different subsets of the fauna that are well-adapted to specific habitat types (and see multivariate analyses, below). 
Formicidae $(2461 \pm 392)$
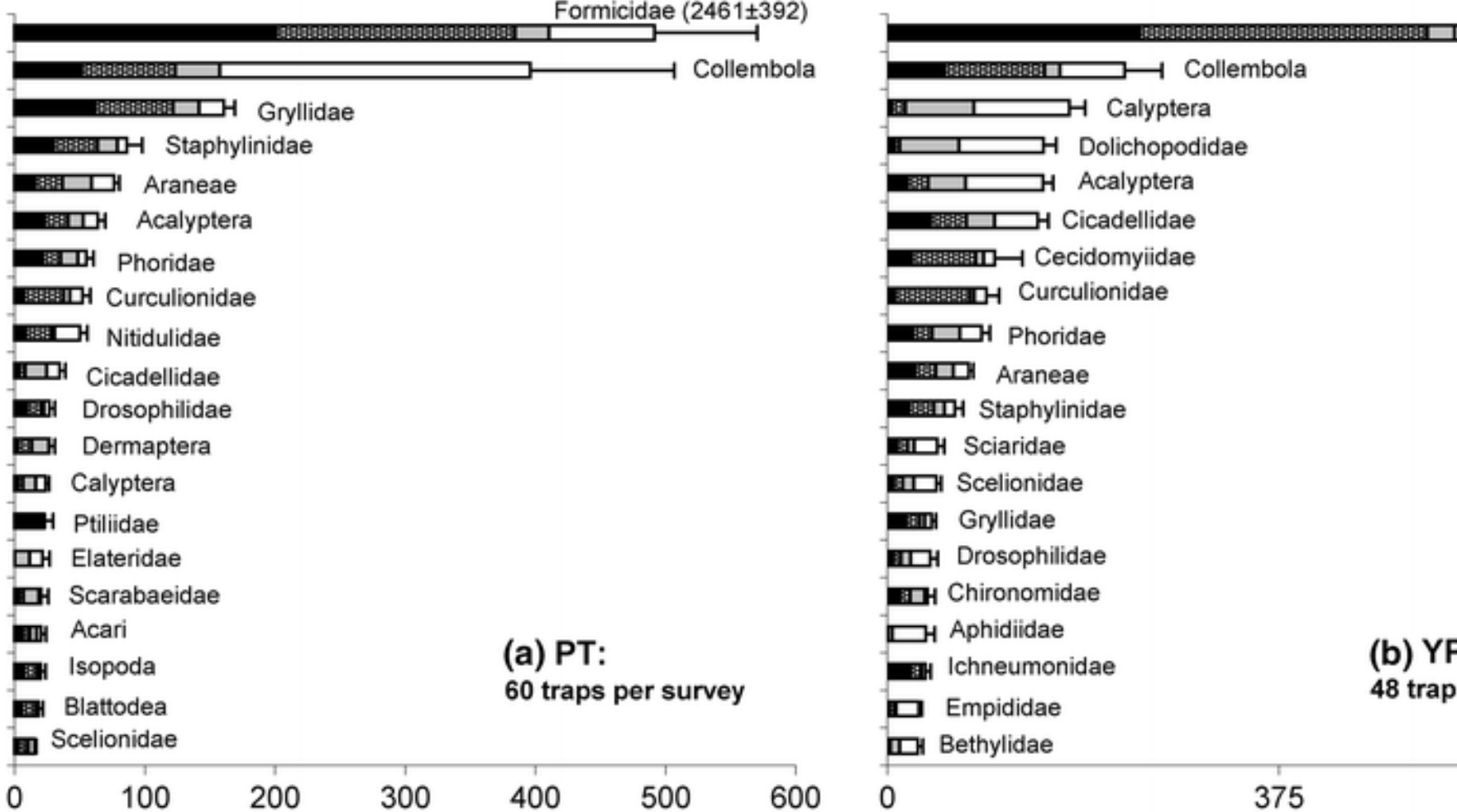

0

375

Cecidomyiidae
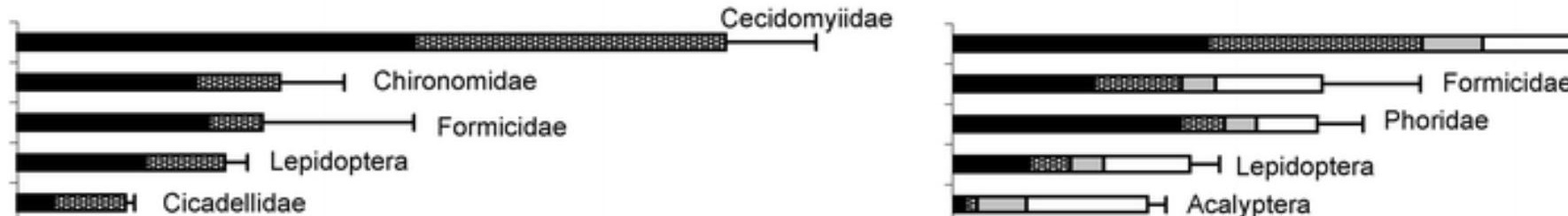

magnger Cicadellidae

man- Sciaridae

Base-1 Phoridae

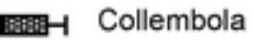

Fiकy Psocoptera

झझझ Ceratopogonidae

Fiar Staphylinidae

ह39 Curculionidae

IFy Culicidae

마 Cixiidae

마 Psychodidae

매 Trixagidae

gan Blattodea

a Araneae

19. Chrysomelidae

(c) FIT:

패 Acalyptera

4 traps per survey

$\begin{array}{llllll} & 1 & 100 & 150 & 200 & 250\end{array}$

250

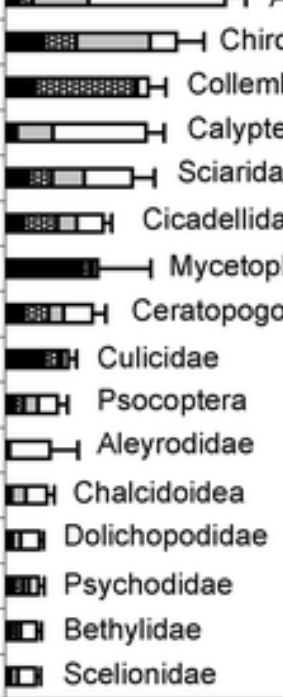

(b) YP

18 trap:

I매 Bethylidae

Mean no. individuals collected per survey

Fig. 3 The 20 most abundant higher taxa collected by each sampling method. Mean ( \pm SE)

number of individuals collected per survey, detailed for old forests (closed bars), young forests 
(stippled bars), savanna (gray bars) and gardens (open bars). Standard errors relate to the mean of total individuals collected per survey for each taxon. For sake of clarity, Formicidae data for PT were all scaled by a factor 0.2 (actual value in brackets)

About half of the higher taxa tested (61 insect families) could be considered as indicators for particular sampling methods (Appendix A: indicator values with $P<0.05,151$ higher taxa tested representing 118 families). These results can be used by entomologists to compare the relative reliability of the four sampling methods used in this study for arthropod taxa. Most of this information has been previously reported in the literature (sometimes without statistical rigor), but other observations may not be widely known and are detailed below.

PTs are known to sample predominantly arthropods foraging on the ground, such as Gryllidae, Carabidae, Formicidae, Acari, Dermaptera and Diplopoda (all with indicator values with $P<0.01$ ). YPTs sampled a mixture of taxa foraging on the ground or flying close to the ground, such as Dolichopodidae, Encyrtidae, Salticidae, Thysanoptera, Ceraphronidae, Sphecidae and Araneae (all with $P<0.01$ ). The relative high catches of Stratiomyidae, Diopsidae and Anthicidae in YPTs are noteworthy. FITs were especially good to collect flying insects that tend to drop when hitting surfaces (many Coleoptera), such as Eucnemidae, Trixagidae, Coniopterygidae, Anthribidae, Cerambycidae, Cleridae, Scyrtidae, Termitidae, Aderidae and Psylloidea (all with $P<0.01$ ). The high incidence of Coniopterygidae and alate Termitidae in the FITs are noteworthy. MTs often collected reasonably good fliers, such as Tabanidae, Buprestidae, Scoliidae, Evaniidae, Eurytomidae, Braconidae and Myrmeleontidae (all with $P<0.01$ ). The good indicator scores for MTs of Buprestidae, Myrmeleontidae and Chrysidae are also noteworthy.

The first and second axes of the DCA explained 23.7 and $11.0 \%$ of variance in the composition of arthropod higher taxa (sum of eigenvalues of DCA $=2.165$ ). They clearly separated samples on the basis of sampling methods (first axis) and habitat types, especially forests and non-forests (second axis; Fig. $\underline{4}$ a). The second axis affected more strongly YPT and MT samples than PT samples (paired $t$-tests for differences in sample scores on axis 2 for PT, YPT and MT samples in forest and non-forest habitats: $t=-2.60$, $P<0.05 ; t=-13.12, P<0.001 ; t=-10.47, P<0.001$, respectively). The CCA confirmed that the effect of sampling method influenced more strongly the composition of higher taxa than the effect of habitats. The first canonical axis explained $49.9 \%$ of the variance in the CCA (21.8\% of the total variance). The dummy variable 'PT' was best correlated with the first axis $(r=-0.85, P<0.001 ;$ Fig. 4 a). The second canonical axis explained $27.2 \%$ of the variance in the CCA (11.9\% of the total variance). The dummy variables 'YPT', 'Garden', and 'Old forest' were best correlated with the second axis ( $r=0.61, r=0.56$ and $r=0.51$, respectively, $P<0.001$; Fig. $\underline{4 a}$ ). 


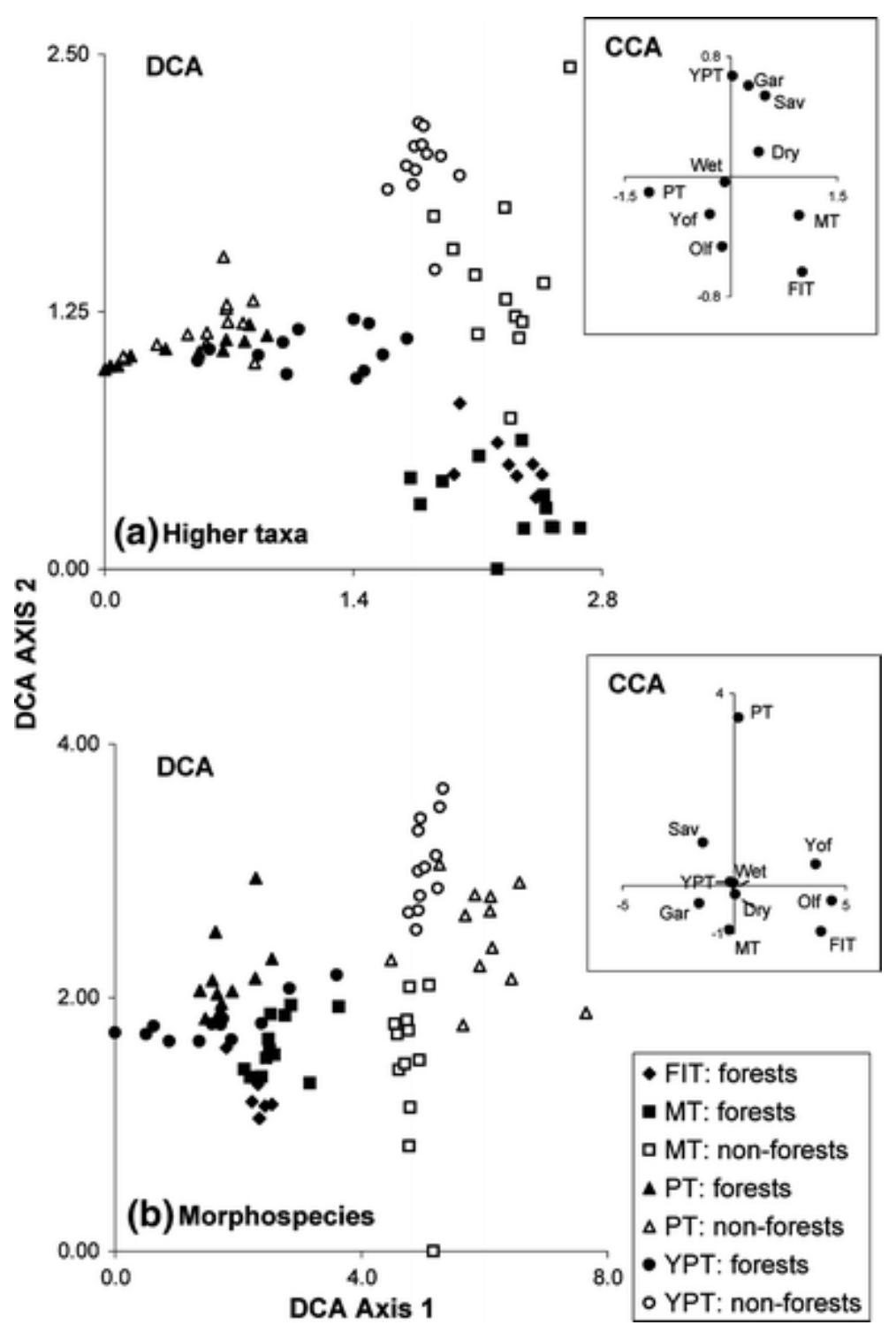

Fig. 4 Multivariate analyses of (a) 151 higher taxa and (b) 86 morphospecies, ordered by sites, methods and seasons. Plot of samples (closed symbols = forests, open symbols = non-forests) in the first and second axis of the DCA. Inset: plot of centroids of environmental variables in the first and second canonical axes of the CCA CCA (Olf = old forest, yof = young forest, sav = savanna, gar = garden, dry = dry season, wet = wet season)

Patterns were different when examining morphospecies composition. In this case, the first and second axes of the DCA explained a lower fraction of variance (9.6 and $6.1 \%$, respectively; sum of eigenvalues $=9.305$ ), emphasizing that many factors may influence morphospecies distribution. The first axis separated samples on the basis of habitat type, especially forests and non-forests, whereas the meaning of the second axis was more difficult to interpret (Fig. 4 b). The first axis affected similarly PTs, YPTs and MTs (paired $t$-tests for differences in sample scores on axis 1 for PT, YPT and MT samples in closed and open habitats: $t=-17.00 ; t=-11.28 ; t=-14.12$; respectively; all with $P<0.001)$. The first canonical axis of the CCA explained $28.8 \%$ of the variance $(9.3 \%$ of 
the total variance) and was best correlated with the dummy variables 'Old forest' and 'Garden' ( $r=0.78$ and -0.64 , respectively, $P<0.001)$. The second canonical axis explained $21.6 \%$ of the variance $6.9 \%$ of the total variance) and was best correlated with the dummy variables 'PT' and 'MT' $(r=0.91$ and -0.57 , respectively, $P<0.001)$. Multivariate analyses of the species dataset were broadly similar to the morphospecies dataset, particularly the first axes of the DCA and CCA being related to habitat type, and are not detailed here.

\section{Discussion \\ Suitability of sampling methods for biological monitoring}

The four sampling methods used in this study were non-destructive and easily deployed and maintained during a year at all studied habitats. However, there are at least four major impediments related to these traps and our study. First, sedentary arthropods were less likely to be collected by these rather passive traps. Thus, measurements of faunal similarity (for example calculated between habitat types) derived from these data are likely to be rather high. Our conclusion that many morphospecies/species are specialized to particular habitats (see below) may thus be further strengthened. Second, these methods were inadequate for many arthropod taxa (e.g., Lepidoptera are better collected with light traps, Kitching et al. 2001). Third, non-forest habitats (savanna and gardens) were better surveyed than forests since traps operated in the understorey. The rich fauna of the forest canopy (Erwin 1983) was probably only occasionally collected, as suggested by steep species accumulation curves and high occurrence of singletons in forests (Fig. 1b, Table $\underline{3}$ ). Last, taxonomic impediment prevented all focal taxa from being examined by taxonomists, although the studies of certain taxa are pending. This limited our analyses related to species richness. In most cases, our species and morphospecies datasets showed similar patterns, but species identifications are crucial for sound biological monitoring.

PTs are inexpensive, easy to deploy in the field and allow high spatial replication for habitat comparisons. However, particular care must be taken to keep the rim of the pitfall level with the ground surface, to ensure maximum efficiency. They need to be serviced often to prevent rain from flooding the trap contents and arthropods to start decomposing. A small roof over the trap may stop rain from diluting the preserving fluid, but this is at the expense of further trap bias (Adis 1979). YPT share most qualities and shortcomings of PTs: being inexpensive; easy to use and possibility of high replication; sensitive to rainfall and frequent servicing needed. However, no roof can be placed over the trap to protect it from rainfall, as this would decrease catches of insects attracted to yellow, which tend to be phytophagous (Kirk 1984). Unlike most authors, we emplaced YPTs with the rim level with the ground surface (Finnamore 1997). This detail explains our high catches of both crawling and flying insects. Abundant material is collected in FITs and MTs (and better preserved than in the case of PTs and YPTs), which takes a lot of time to sort. However, by restricting operations to a short period with frequent servicing 
(3 days at weekly intervals, such as in the present study), one may greatly decrease catches size and allow one to consider all taxa within (the smaller) samples. For longterm studies and monitoring, this approach may result in more representative samples (Gadagkar et al. 1990). Both types of traps are expensive and, thus, spatial replication is more difficult to achieve than with the other two methods. The larger FITs and MTs are also more prone to disruption from humans and animals (with concomitant difficulty and costs to replace them) than the smaller PTs and YPTs, particularly in Africa in areas where large mammals are abundant.

\section{Complementarity of sampling methods and reliability for collecting particular taxa}

Sampling methods strongly influenced arthropod composition in trap catches, as they targeted different components of the fauna, either foraging on the ground (PTs, YPTs) or flying low in the vegetation (YPTs, FITs, MTs). Trap complementarity was highest for traps best designed to exploit these different behaviors, PTs and MTs. Each sampling method was biased towards specific higher taxa and morphospecies, resulting in different species rank abundance distributions. Most of the 35 morphospecies that were collected by all four collecting methods were more readily sampled by a particular method. As a result, faunal similarities calculated between the catches of different sampling methods were low. The implications are clear: a range of sampling methods (at the expense of lower replication) is likely to yield more diverse material for inventorying and monitoring arthropods than any single method operated with high replication (Noyes 1989; Gadagkar et al. 1990; Stork 1994; Basset et al. 1997; Longino and Colwell 1997; Kitching et al. 2001). Arguably, more systemic sampling methods exist than used in this study (e.g., pyrethrum knockdown, net sweeping, e.g., Noyes 1989; Watt et al. 1997), but they are unsuitable for long-term monitoring as they dramatically disturb study sites by fumigation and trampling.

Further, the extensive dataset of this study allowed statistical testing of the reliability of sampling methods used in this study for 118 arthropod families (in terms of relative abundance, Appendix A). This statistical approach is more accurate than relying on scientific tradition for choice of taxa and methods, which often prevails in the entomological literature (Kitching et al. 2001).

\section{Effects of habitat structure on trap efficiency}

The effect of habitat structure on the trappability of different taxa is an important topic (Melbourne 1999). However true faunistic differences between habitat types, such as those considered in the present study are likely to be far more significant, as suggested by the magnitude of faunal turnover observed (only 39 morphospecies common to all habitats, $2.4 \%$ of all morphospecies sorted; data presented and discussed elsewhere). As far as higher taxa are concerned, given that sampling methods had a larger impact on arthropod composition than habitat type (Fig. 4 a), the most efficient method for a particular taxon is likely to remain the same across all habitat types. That said, we 
observed that the higher taxa composition of MTs varied more between forests and nonforest habitats than that of PTs, YPTs being intermediate in this regard. MTs and YPTs may be more efficient in open habitats because of increased visibility and attractiveness (Noyes 1989). Alternatively, MTs and YPTs are more likely to collect mobile taxa that may forage in different habitats. Interestingly, these patterns were different when considering the morphospecies/species composition of trap catches: the effects of habitat type were stronger than the effects of sampling method. This confirms that many morphospecies/species are specialized foragers in particular habitats and that datasets sorted at the level of species/morphospecies are much more discriminating with regard to arthropod composition in different habitats than those sorted at the level of higher taxa (Basset et al. 2004a). This implies that monitoring should be preferably performed at the level of morphospecies/species and that for this type of data differences in trap efficiency or taxa trappability between habitat types may be neglected, as far as habitat types remain well contrasted and contain dissimilar fauna.

\section{Conclusions and recommendations}

The two concepts of inventorying and monitoring biodiversity are connected, since baseline data are needed for monitoring (Rohr et al. 2007). For inventorying purposes, a combination of methods targeting different faunal components may be optimal, as they may collect a wider range of taxa than a single method (Noyes 1989; Gadagkar et al. 1990; Stork 1994; Basset et al. 1997; Longino and Colwell 1997; Kitching et al. 2001). Including a few MTs in the protocol may be valuable since they accumulate faster species in trap catches and provide high quality material for further taxonomic analyses. Note that a possible improvement of the protocol developed in the present study would be to establish more sites for each habitat type (i.e., nine sites per habitat instead of three) and to randomly move the 12 traps operating within this set of sites every month (or other relevant period). The amount of material collected would be similar but, most likely, more diverse. Further, it would improve statistical power, with analyses being less-site and more habitat-dependent. Adequate inventory of the canopy fauna, often different from that in the understorey within tall closed rainforests (Basset et al. 2003), remains a challenge (Basset et al. 1997). With regard specifically to long-term monitoring, one possibility may include operating compact FITs, modified YPTs or automatic light traps lifted on pulleys high in the canopy (Springate and Basset 1996; Wolda et al. 1998; De Dijn 2003).

For general monitoring purposes, the situation is more complex, as species abundance in traps ideally needs to reflect actual species abundance. Given that each method tends to target a different component of the fauna and has its own biases, it would be preferable to statistically analyze species data separately for each sampling method, the results of one complementing the results of the other(s). In case only one sampling method can be deployed, YPTs represent an acceptable compromise, as they samples both crawling and flying arthropods and accumulate specimens and species reasonably fast. Further, since higher taxa composition in YPTs differed consistently between forest and non-forest habitats than in MTs or PTs, YPTs may be particularly useful for monitoring arthropod recovery in degraded and open habitats. 
As noted in the introduction, several quantitative protocols exist to survey specific arthropod taxa in the tropics. For biological monitoring, it may be possible to implement in parallel taxa-specific protocols, but this approach is likely to be obtrusive (by trampling required to performed 5-10 protocols alone), or even destructive (e.g., ant and termite protocols, Agosti et al. 2000; Jones and Eggelton 2000), or time-consuming (as different training skills may be required for operators). The following alternative, based on the present study, may be considered: implement a common set of passive, nonobtrusive sampling methods (such as PTs, YPTs and MTs), extract focal taxa with the help of local parataxonomists (Basset et al. 2004b), and refine species identifications with taxonomists' feedback. In addition to this multi-taxic monitoring programme, 1-3 taxaspecific protocols could be implemented in parallel, to validate the results of the wider monitoring programme. This strategy has at least four added advantages: (1) development of baseline datasets that are wider in taxonomic scope; (2) monitoring of a larger number of focal taxa belonging to different functional guilds; (3) long-term studies with nondisruptive methods may allow collection of rare species, which represent a substantial proportion of tropical arthropod assemblages (Novotny and Basset 2000); and (4) wider training base for parataxonomists.

In conclusion, taxa-specific sampling protocols are certainly the best strategy when evaluating the effects of anthropogenic disturbance on particular arthropod taxa. However, for the purpose of monitoring large and diverse arthropod assemblages in the long-term, a protocol based on operating a set of different and non-disruptive traps appears superior in design and rewards than summing a series of taxa-specific protocols.

Acknowledgements F. Dallmeier, J. Comiskey, M. Lee, J. Mavoungou and J. B. Mikissa helped to implement the project. Parataxonomists B. Amvame, N. Koumba, S. Mboumba Ditona, G. Moussavou, P. Ngoma, J. Syssou, L. Tchignoumba and E. Tobi collected, processed, sorted and data-based most of the insect material with great competence. J. Raymakers and S. Mboumba Ditona provided the vegetational data. M. Foldvari, S. W. Lingafelter and F. C. Thompson helped with pipunculid, cerambycid and syrphid identifications, respectively. V. Novotny commented on an early draft of the manuscript. The project was funded by the Smithsonian Institution, National Zoological Park, Conservation and Research Center/MAB Program through grants from the Shell Foundation and Shell Gabon. This is contribution No. 84 of the Gabon Biodiversity Program.

\section{Appendix A: Results of species indicator analysis with regard to sampling methods for the 151 most abundant higher taxa}

\begin{tabular}{|l|l|l|l|l|}
\hline Taxa & Method & Indicat. val. (\%) & $\boldsymbol{P}$-value \\
\hline Acari & PT & 54.8 & 0.001 \\
\hline Araneae & YPT & 38.1 & 0.008 \\
\hline Salticidae & YPT & 65.7 & 0.001 \\
\hline
\end{tabular}




\begin{tabular}{|c|c|c|c|}
\hline Taxa & Method & Indicat. val. (\%) & $P$-value \\
\hline \multicolumn{4}{|l|}{ Archaeognatha } \\
\hline Meinertellidae & MT & 14.3 & 0.755 \\
\hline Blattodea & FIT & 37.7 & 0.219 \\
\hline \multicolumn{4}{|l|}{ Coleoptera } \\
\hline Aderidae & FIT & 62.8 & 0.008 \\
\hline Anthicidae & YPT & 52.2 & 0.032 \\
\hline Anthribidae & FIT & 69.8 & 0.001 \\
\hline Bostrichidae & MT & 28.7 & 0.280 \\
\hline Bruchidae & MT & 39.1 & 0.452 \\
\hline Buprestidae & MT & 78.0 & 0.001 \\
\hline Carabidae & PT & 68.7 & 0.001 \\
\hline Cerambycidae & FIT & 63.0 & 0.001 \\
\hline Chrysomelidae & MT & 32.9 & 0.746 \\
\hline Clambidae & YPT & 40.5 & 0.224 \\
\hline Cleridae & FIT & 78.9 & 0.002 \\
\hline Coccinellidae & YPT & 41.7 & 0.296 \\
\hline Corylophidae & FIT & 39.4 & 0.283 \\
\hline Cucujoidea & PT & 26.2 & 0.431 \\
\hline Curculionidae & YPT & 47.4 & 0.349 \\
\hline Elateridae & PT & 34.4 & 0.644 \\
\hline Endomychidae & MT & 74.7 & 0.013 \\
\hline Eucnemidae & FIT & 83.9 & 0.001 \\
\hline Histeridae & YPT & 43.2 & 0.109 \\
\hline Hydrophilidae & PT & 61.6 & 0.055 \\
\hline Lagriidae & FIT & 34.4 & 0.174 \\
\hline Leiodidae & YPT & 35.4 & 0.635 \\
\hline Mordellidae & MT & 44.4 & 0.076 \\
\hline Mycetophagidae & FIT & 26.5 & 0.337 \\
\hline Nitidulidae & PT & 54.5 & 0.011 \\
\hline Phalacridae & FIT & 40.7 & 0.062 \\
\hline Pselaphidae & FIT & 47.4 & 0.018 \\
\hline Ptiliidae & PT & 51.9 & 0.091 \\
\hline Scarabaeidae & MT & 37.8 & 0.480 \\
\hline Scydmaenidae & FIT & 35.3 & 0.461 \\
\hline
\end{tabular}




\begin{tabular}{|c|c|c|c|}
\hline Taxa & Method & Indicat. val. (\%) & $P$-value \\
\hline Scyrtidae & FIT & 75.3 & 0.004 \\
\hline Staphylinidae & PT & 40.3 & 0.040 \\
\hline Tenebrionidae & MT & 41.8 & 0.247 \\
\hline Trixagidae & FIT & 81.7 & 0.001 \\
\hline Coleoptera: unknown & PT & 39.9 & 0.103 \\
\hline Collembola & PT & 48.6 & 0.019 \\
\hline Entomobryidae & MT & 39.2 & 0.112 \\
\hline Dermaptera & PT & 82.2 & 0.002 \\
\hline Diplopoda & PT & 67.7 & 0.009 \\
\hline \multicolumn{4}{|l|}{ Diptera } \\
\hline Acalyptera & MT & 47.2 & 0.034 \\
\hline Anthomyiidae & MT & 41.2 & 0.021 \\
\hline Asilidae & MT & 61.5 & 0.013 \\
\hline Calliphoridae & YPT & 47.4 & 0.047 \\
\hline Calyptera & YPT & 51.0 & 0.031 \\
\hline Cecidomyiidae & MT & 48.8 & 0.063 \\
\hline Ceratopogonidae & MT & 55.0 & 0.013 \\
\hline Chironomidae & FIT & 53.2 & 0.018 \\
\hline Culicidae & MT & 59.8 & 0.087 \\
\hline Diopsidae & YPT & 53.2 & 0.024 \\
\hline Dolichopodidae & YPT & 77.2 & 0.001 \\
\hline Drosophilidae & YPT & 43.8 & 0.035 \\
\hline Empididae & YPT & 52.2 & 0.180 \\
\hline Limoniidae & MT & 48.4 & 0.043 \\
\hline Micropezidae & YPT & 61.3 & 0.055 \\
\hline Muscidae & YPT & 25.6 & 0.194 \\
\hline Mycetophilidae & MT & 78.5 & 0.059 \\
\hline Phoridae & MT & 65.0 & 0.016 \\
\hline Pipunculidae & MT & 47.1 & 0.031 \\
\hline Platystomatidae & YPT & 38.4 & 0.088 \\
\hline Psychodidae & MT & 38.8 & 0.145 \\
\hline Sarcophagidae & YPT & 49.4 & 0.040 \\
\hline Scatopsidae & MT & 70.6 & 0.064 \\
\hline Sciaridae & MT & 45.8 & 0.014 \\
\hline
\end{tabular}




\begin{tabular}{|c|c|c|c|}
\hline Taxa & Method & Indicat. val. (\%) & $P$-value \\
\hline Stratiomyidae & YPT & 48.6 & 0.023 \\
\hline Syrphidae & MT & 63.3 & 0.046 \\
\hline Tabanidae & MT & 81.9 & 0.001 \\
\hline Tephritidae & MT & 61.1 & 0.191 \\
\hline Tipulidae & MT & 54.9 & 0.021 \\
\hline Diptera: unknown & YPT & 61.9 & 0.011 \\
\hline Embioptera & YPT & 31.2 & 0.300 \\
\hline \multicolumn{4}{|l|}{ Hemiptera (Heteropterans) } \\
\hline Anthocoridae & FIT & 34.2 & 0.171 \\
\hline Ceratocombidae & FIT & 42.5 & 0.029 \\
\hline Coreidae & YPT & 29.4 & 0.313 \\
\hline Cydnidae & PT & 40.8 & 0.225 \\
\hline Lygaeidae & YPT & 36.2 & 0.453 \\
\hline Miridae & MT & 36.7 & 0.232 \\
\hline Reduvidae & MT & 30.7 & 0.589 \\
\hline Salpingidae & FIT & 27.3 & 0.355 \\
\hline Heteroptera: juveniles & FIT & 21.4 & 0.863 \\
\hline Heteroptera: unknown (Homopterans) & FIT & 32.0 & 0.434 \\
\hline Achilidae & FIT & 53.4 & 0.040 \\
\hline Aleyrodidae & MT & 58.3 & 0.328 \\
\hline Aphidoidea & YPT & 54.5 & 0.098 \\
\hline Aphrophoridae & YPT & 78.9 & 0.010 \\
\hline Cercopidae & YPT & 46.7 & 0.043 \\
\hline Cicadellidae & YPT & 38.9 & 0.035 \\
\hline Cixiidae & FIT & 51.5 & 0.035 \\
\hline Coccoidea & PT & 40.6 & 0.081 \\
\hline Delphacidae & YPT & 74.5 & 0.012 \\
\hline Derbidae & MT & 57.2 & 0.043 \\
\hline Fulgoridae & MT & 25.6 & 0.395 \\
\hline Meenoplidae & MT & 57.8 & 0.079 \\
\hline Psylloidea & FIT & 49.3 & 0.008 \\
\hline Fulgoroidea: juveniles & MT & 39.0 & 0.419 \\
\hline \multicolumn{4}{|l|}{ Hymenoptera } \\
\hline Apidae & MT & 53.3 & 0.045 \\
\hline
\end{tabular}




\begin{tabular}{|c|c|c|c|}
\hline Taxa & Method & Indicat. val. (\%) & $P$-value \\
\hline Apoidea & MT & 34.3 & 0.380 \\
\hline Aulacidae & MT & 46.9 & 0.045 \\
\hline Bethylidae & MT & 42.4 & 0.194 \\
\hline Braconidae & MT & 64.7 & 0.006 \\
\hline Ceraphronidae & YPT & 73.4 & 0.006 \\
\hline Chalcididae & MT & 65.9 & 0.014 \\
\hline Chalcidoidea & MT & 49.4 & 0.124 \\
\hline Chrysididae & MT & 42.6 & 0.035 \\
\hline Crabronidae & MT & 46.5 & 0.067 \\
\hline Cynipoidea & MT & 61.4 & 0.014 \\
\hline Diapriidae & MT & 42.1 & 0.237 \\
\hline Elasmidae & MT & 31.1 & 0.113 \\
\hline Encyrtidae & YPT & 73.3 & 0.001 \\
\hline Eucoilidae & YPT & 16.4 & 0.570 \\
\hline Eupelmidae & MT & 38.4 & 0.129 \\
\hline Eurytomidae & MT & 66.9 & 0.002 \\
\hline Evaniidae & MT & 72.3 & 0.002 \\
\hline Formicidae & PT & 66.6 & 0.001 \\
\hline Halictidae & MT & 54.4 & 0.086 \\
\hline Ichneumonidae & YPT & 58.5 & 0.045 \\
\hline Mutilidae & YPT & 42.7 & 0.171 \\
\hline Platygastridae & MT & 30.2 & 0.577 \\
\hline Pompilidae & YPT & 47.8 & 0.018 \\
\hline Proctotrupoidea & MT & 30.9 & 0.236 \\
\hline Scelionidae & YPT & 45.2 & 0.135 \\
\hline Scoliidae & MT & 62.2 & 0.001 \\
\hline Sphecidae & YPT & 54.2 & 0.007 \\
\hline Tiphiidae & YPT & 42.8 & 0.096 \\
\hline Torymidae & MT & 58.0 & 0.016 \\
\hline Vespidae & YPT & 50.1 & 0.029 \\
\hline Hymenoptera: juveniles & MT & 31.8 & 0.405 \\
\hline Isopoda & PT & 57.5 & 0.029 \\
\hline Isoptera & FIT & 39.0 & 0.139 \\
\hline Termitidae & FIT & 55.6 & 0.005 \\
\hline
\end{tabular}




\begin{tabular}{|c|c|c|c|}
\hline Taxa & Method & Indicat. val. (\%) & $P$-value \\
\hline Lepidoptera & MT & 54.5 & 0.017 \\
\hline Geometridae & YPT & 31.1 & 0.384 \\
\hline Lepidoptera: juveniles & PT & 39.7 & 0.192 \\
\hline Mantodea & MT & 43.2 & 0.122 \\
\hline \multicolumn{4}{|l|}{ Neuroptera } \\
\hline Coniopterygidae & FIT & 78.3 & 0.001 \\
\hline Myrmeleontidae & MT & 68.1 & 0.007 \\
\hline Opiliones & MT & 18.7 & 0.865 \\
\hline \multicolumn{4}{|l|}{ Orthoptera } \\
\hline Acrididae & YPT & 37.3 & 0.274 \\
\hline Gryllidae & PT & 73.0 & 0.001 \\
\hline Pyrgomorphidae & PT & 25.3 & 0.490 \\
\hline Tetrigidae & PT & 41.9 & 0.068 \\
\hline Tettigoniidae & MT & 33.1 & 0.362 \\
\hline Tridactylidae & YPT & 36.6 & 0.270 \\
\hline Pseudoscorpiones & PT & 21.6 & 0.521 \\
\hline Psocoptera & FIT & 47.5 & 0.043 \\
\hline Thysanoptera & YPT & 65.7 & 0.002 \\
\hline Trichoptera & FIT & 51.7 & 0.014 \\
\hline
\end{tabular}

Taxa are listed alphabetically by order, detailing the sampling method for which the maximum indicator value was recorded; the maximum indicator value; and the $P$-value of Monte Carlo permutations testing the statistical significance of the maximum indicator value. Indicator values for taxa indicated in bold are significant with $P<0.05$

\section{References}

Adis J (1979) Problems of interpreting arthropod sampling with pitfall traps. Zool Anz 202:177184

Adis J, Basset Y, Floren A, Hammond PM, Linsenmair KE (1998) Canopy fogging of an overstorey tree - recommendations for standardization. Ecotropica 4:93-97

Agosti D, Majer JD, Alonso LE, Schultz TR (2000) Ants. Standards methods for measuring and monitoring biodiversity. Smithsonian Institution Press, Washington

Alonso A, Lee ME, Campbell P, Pauwels OSG, Dallmeier F (eds) (2006) Gamba, Gabon: Biodiversité d'une forêt équatoriale africaine/Gamba, Gabon: Biodiversity of an equatorial African rainforest, vol 12. Bull. Biol. Soc., Washington, pp 1-436 
Basset Y, Aberlenc H-P, Springate ND, Delvare G (1997) A review of methods for collecting arthropods in tree canopies. In: Stork NE, Adis JA, Didham RK (eds) Canopy arthropods. Chapman and Hall, London, pp 27-52

Basset Y, Charles E, Hammond DS, Brown VK (2001) Short-term effects of canopy openness on insect herbivores in a rain forest in Guyana. J Appl Ecol 38:1045-1058

cross ${ }^{\text {ref }}$

Basset Y, Novotny V, Miller SE, Kitching RL (eds) (2003) Arthropods of tropical forests. Spatiotemporal dynamics and resource use in the canopy. Cambridge University Press, Cambridge

Basset Y, Mavoungou JF, Mikissa JB, Missa O, Miller SE, Kitching RL, Alonso A (2004a)

Discriminatory power of different arthropod data sets for the biological monitoring of anthropogenic disturbance in tropical forests. Biodiv Conserv 13:709-732

[SpringerLink]

Basset Y, Novotny V, Miller SE, Weiblen GD, Missa O, Stewart AJA (2004b) Conservation and biological monitoring of tropical forests: the role of parataxonomists. J Appl Ecol 41:163-174

cross ${ }^{\text {ref }}$

Basset Y, Missa O, Alonso A, Miller SE, Curletti G, De Meyer M, Eardley C, Lewis OT, Mansell MW, Novotny V, Wagner T (2008) Choice of metrics for studying arthropod responses to habitat disturbance: one example from Gabon. Ins Conserv Div (in press)

Borcard D, Legendre P, Drapeau P (1992) Partialling out the spatial component of ecological variation. Ecology 73:1045-1055

cross ref

Bowden J (1982) An analysis of the factors affecting catches of insects in light traps. Bull Ent Res 72:535-556

Colwell RK (2005) EstimateS: Statistical estimation of species richness and shared species from samples. Version 7.5. Persistent URL http://www.purl.oclc.org/estimates

Colwell RK, Coddington JA (1994) Estimating terrestrial biodiversity through extrapolation. Phil Trans R Soc Lond B 345:101-118

cross ${ }^{\text {ref }}$ ChemPort

Conrad KF, Fox R, Woiwod IP (2007) Monitoring biodiversity: measuring long-term changes in insect abundance. In: Stewart AJA, New TR, Lewis OT (eds) Insect conservation biology. CABI Publishing, Wallingford, pp 203-225

De Dijn B (2003) Vertical stratification of flying insects in a Surinam lowland rainforest. In: Basset Y, Novotny V, Miller SE, Kitching RL (eds) Arthropods of tropical forests. Spatio-temporal dynamics and resource use in the canopy. Cambridge University Press, Cambridge, pp 110-122

DeVries PJ, Walla TR (2001) Species diversity and community structure in neotropical fruit- 
feeding butterflies. Biol J Linn Soc 74:1-15

cross ref

Didham RK, Ghazoul J, Stork NE, Davis AJ (1996) Insects in fragmented forests: a functional approach. Trends Ecol Evol 11:255-260

cross ref

Dufrêne M, Legendre P (1997) Species assemblages and indicator species: the need for a flexible assymetrical approach. Ecol Monogr 67:345-366

Dunn RR (2005) Modern insect extinctions, the neglected majority. Conserv Biol 19:1030-1036 cross ref

Erwin TL (1983) Tropical forest canopies: the last biotic frontier. Bull Ent Soc Am 29:14-19

Finnamore A (1997) Long-term monitoring of arthropod fauna in the Lower Urubamba Region. In: Dallmeier F, Alonso A (eds) Biodiversity assessment and monitoring of the lower Urubamba region, Peru. San Martin-3 and Cashiriari-2 well sites. Smithsonina Institution, SI/MAB

Biodiversity Program, Washington, D.C., pp 177-211

Gadagkar R, Chandrashekara K, Nair P (1990) Insect species diversity in the tropics: sampling methods and a case study. J Bombay Nat Hist Soc 87:337-353

Grassle JF, Smith W (1976) A similarity measure sensitive to the contribution of rare species and its use in investigation of variation in marine benthic communities. Oecologia 25:13-22

[SpringerLink]

Jones DT, Eggelton P (2000) Sampling termite assemblages in tropical forests: testing a rapid biodiversity assessment protocol. J Appl Ecol 37:191-203

\section{cross ${ }^{\text {ref }}$}

King JA, Porter SD (2005) Evaluation of sampling methods and species richness estimators for ants in upland ecosystems in Florida. Environ Entomol 34:1566-1578

Kirk WDJ (1984) Ecologically selective coloured traps. Ecol Entomol 9:35-41

Kitching RL, Li D, Stork NE (2001) Assessing biodiversity 'sampling packages': how similar are arthropod asemblages in different tropical rainforests? Biodiv Conserv 10:793-813

[SpringerLink]

Kotze DJ, Samways MJ (1999) Support for the multi-taxa approach in biodiversity assessment, as shown by epigaeic invertebrates in an Afromontane forest archipelago. J Ins Conserv 3:125143

[SpringerLink]

Kremen C, Colwell RK, Erwin TL, Murphy DD, Noss RF, Sanjayan MA (1993) Terrestrial arthropod assemblages: their use in conservation planning. Conserv Biol 7:796-808 


\section{cross ref}

Kremen C, Merenlender AM, Murphy DD (1994) Ecological monitoring: a vital need for integrated conservation and development programs in the tropics. Conserv Biol 8:388-397

cross ref

Lawton JH, Bignell DE, Bolton B, Bloemers GF, Eggleton P, Hammond PM, Hodda M, Holt RD, Larsen TB, Mawdsley NA, Stork NE, Srivastava DS, Watt AD (1998) Biodiversity inventories, indicator taxa and effects of habitat modification in tropical forest. Nature 391:72-76 cross ref ChemPort

Leps J, Smilauer P (2003) Multivariate analysis of ecological data using CANOCO. Cambridge University Press, Cambridge

Lewis OT, Basset Y (2007) Insect conservation in tropical forests. In: Stewart AJA, New TR, Lewis OT (eds) Insect conservation biology. CABI Publishing, Wallingford, pp 34-56

Longino JT, Colwell RC (1997) Biodiversity assessment using structured inventory: capturing the ant fauna of a tropical rain forest. Ecol Appl 7:1263-1277

$<$ Occurrence Type="DOI" $><$ Handle $>10.1890 / 1051-$

0761(1997)007[1263:BAUSIC]2.0.CO;2</Handle></Occurrence>

Magurran AE (1988) Ecological diversity and its measurement. Croom Helm, London

May RM, Lawton JH, Stork NE (1995) Assessing extinction rates. In: Lawton JH, May RM (eds)

Extinction rates. Oxford University Press, Oxford, pp 1-24

McCune B, Medford MJ (1999) Multivariate analysis of ecological data version 4.10. MjM

Software, Gleneden Beach, Oregon

Melbourne BA (1999) Bias in the effect of habitat structure on pitfall traps: an experimental evaluation. Aust J Ecol 24:228-239

cross ${ }^{\text {ref }}$

Millennium Ecosystem Assessment (2005) Ecosystems and human well-being: biodiversity synthesis. World Resource Institute, Washington

Moran CV, Southwood TRE (1982) The guild composition of arthropod communities in trees. J Anim Ecol 51:289-306

cross ref

Moritz C, Richardson KS, Ferrier S, Monteith GB, Stanisic J, Williams SE, Whiffin T (2001) Biogeographical concordance and efficiency of taxon indicators for establishing conservation priority in a tropical rainforest biota. Proc R Soc Lond B 268:1875-1881

cross ${ }^{\text {ref }}$ ChemPort

Muirhead-Thomson RC (1991) Trap responses of flying insects. Academic Press, London 
Niemelä J (2000) Biodiversity monitoring for decision-making. Ann Zool Fennici 37:307-317

Novotny V, Basset $Y$ (2000) Rare species in communities of tropical insect herbivores: pondering the mystery of singletons. Oikos 89:564-572

cross ref

Noyes JS (1989) A study of five methods of sampling Hymenoptera (Insecta) in a tropical rainforest, with special reference to the Parasitica. J Nat Hist 23:285-298

cross ref

Rohr JR, Mahan CG, Kim KC (2007) Developing a monitoring program for invertebrates: guidelines and a case study. Conserv Biol 21:422-433

PubMed cross ${ }^{r}$ ef

Sala OE, Chapin FS III, Armesto JJ, Berlow E, Bloomfield J, Dirzo R, Huber-Sanwald E, Huenneke LF, Jackson RB, Kinzig A, Leemans R, Lodge DM, Mooney HA, Oesterheld M, LeRoy Poff N, Syrkes MT, Walker BH, Walker M, Wall DH (2000) Global biodiversity scenarios for the year 2100. Nature 287:1770-1774

ChemPort

Southwood TRE, Henderson PA (2000) Ecological methods, 3rd edn. Blackwell Publishing, Oxford

Sparrow HR, Sisk TD, Ehrlich PR, Murphy DD (1994) Techniques and guidelines for monitoring Neotropical butterflies. Conserv Biol 8:800-809

cross ref

Springate ND, Basset $Y$ (1996) Diel activity of arboreal arthropods associated with Papua New Guinean trees. J Nat Hist 30:101-112

cross ref

Stork NE (1994) Inventories of biodiversity: more than a question of numbers. In: Forey PL, Humphries CJ, Vane-Wright RI (eds) Systematics and conservation evaluation. Clarendon Press, Oxford, pp 81-100

Stork NE, Brendell MJD (1993) Arthropod abundance in lowland rain forest of Seram. In: Edwards ID, MacDonald AA, Proctor J (eds) Natural history of Seram, Maluku, Indonesia. Intercept, Andover, pp 115-130

Stork NE, Samways MJ, Eeley HAC (1995) Inventorying and monitoring biodiversity. Trends Ecol Evol 11:39-40

cross ${ }^{\text {ref }}$

ter Braak CJF, Smilauer P (1998) CANOCO reference manual and user's guide to Canoco for Windows: software for Canonican community ordination (Version 4). Mirocomputer Power, Ithaca 
Townes H (1972) A light-weight Malaise trap. Ent News 83:239-247

Underwood EC, Fisher BL (2006) The role of ants in conservation monitoring: if, when and how. Biol Conserv 132:166-182

cross $r$

Watt AD, Stork NE, McBeath C, Lawson GL (1997) Impact of forest management on insect abundance and damage in a lowland tropical forest in southern Cameroon. J Appl Ecol 34:985998

cross ref

Wolda H, O'Brien CW, Stockwell HP (1998) Weevil diversity and seasonality in tropical Panama as deduced from light-trap catches (Coleoptera: Curculionoidea). Smiths Contr Zool 590:1-79

Yoccoz NG, Nichols JD, Boulinier T (2001) Monitoring of biological diversity in space and time. Trends Ecol Evol 16:446-453

cross ref 